Revta brasil. Bot., São Paulo, V.22, n.2, p.175-184, ago. 1999

\title{
Estudo anatômico comparativo do lenho e da casca de duas espécies de Eugenia L. (Myrtaceae)
}

\author{
PATRICIA SOFFIATTI ${ }^{1,2}$ e VERONICA ANGYALOSSY-ALFONSO ${ }^{1,3}$
}

(recebido em 03/12/97; aceito em 17/02/99)

\begin{abstract}
Comparative anatomy study on wood and bark of two Eugenia L. species (Myrtaceae)). The wood and bark anatomy of Eugenia cerasiflora Miq. and E. uniflora L. is described. The species have a uniform wood anatomy, whereas the bark anatomy is highly variable between species. Based on wood anatomy the genus can be distinguished by the type of axial parenchyma and presence of crystals. The bark is distinguished based on the type and distribution of sclerenchymatic tissues, the types of periderm and rhytidome. The differences found in wood and bark anatomy among species show their importance for identification purposes.

RESUMO - (Estudo anatômico comparativo do lenho e da casca de duas espécies de Eugenia L. (Myrtaceae)). A anatomia do lenho e da casca de Eugenia cerasiflora Miq. e E. uniflora L. são descritas no presente trabalho. As espécies apresentam a anatomia do lenho relativamente uniforme, enquanto a anatomia da casca mostra diferenças mais evidentes. As espécies diferenciam-se, em relação ao lenho, quanto ao tipo de parênquima axial e presença de cristais. Quanto à casca tem-se, como características que individualizam as espécies, o tipo e o arranjo das células esclerificadas no floema, tipo de periderme e presença de ritidoma. O presente trabalho mostra a importância da anatomia da casca, aliada à do lenho, para a separação e identificação de espécies.
\end{abstract}

Key words - Wood anatomy, bark anatomy, Myrtaceae, Eugenia

\section{Introdução}

A anatomia do lenho vem se consolidando como um importante instrumento na solução de questões taxonômicas, evolutivas e ecológicas. Os estudos sobre a anatomia da casca se iniciaram mais tarde, com o objetivo de complementar os do lenho, sendo que o atual interesse nesses estudos se deve, entre outros motivos, ao auxílio na identificação e separação de espécies, como comprovado por diversos autores (Richter 1981, Trockenbrodt \& Parameswaran 1986, Angyalossy-Alfonso \& Richter 1991).

Os primeiros trabalhos utilizando a anatomia do lenho na família Myrtaceae foram realizados com o gênero Eucalyptus por Dadswell \& Burnell (1932) e Dadswell (1972), apresentando as características qualitativas e quantitativas de 185 espécies. A anatomia da madeira dessa família foi descrita também por Metcalfe \& Chalk (1950) e Van Vliet \& Baas (1984). Détienne \& Jacquet (1983), mencionam a dificuldade de separação dos gêneros dessa família com base na anatomia do lenho, devido à homogeneidade en-

1. Departamento de Botânica, Instituto de Biociências, Universidade de São Paulo, Caixa Postal 11461, 05422-970 São Paulo, SP, Brasil

2. Bolsista de IC - FAPESP - E-mail: soffiatt@usp.br

3. Bolsista do CNPq - E-mail: valfonso@ib.usp.br tre alguns, aliada à heterogeneidade entre espécies de um mesmo gênero.

Os primeiros estudos de casca de espécies da família Myrtaceae foram realizados por Chattaway (1953), também com o gênero Eucalyptus. A autora demonstra a importância da casca no estudo de diferentes espécies do gênero, relacionando sua diversidade anatômica à diversidade de sua morfologia externa.

No Brasil, os estudos de anatomia do lenho e da casca realizados por Angyalossy-Alfonso (1983, 1987) e de anatomia do lenho realizados por Tomazello Filho (1985) com espécies de Eucalyptus introduzidas, trouxeram contribuições para a identificação dentro do gênero.

Em relação às espécies nativas de Myrtaceae citam-se os trabalhos de Détienne \& Jacquet (1983) e de Dias-Leme et al. (1995). O primeiro apresenta as características anatômicas, visando à identificação de oito gêneros da Amazônia, totalizando 14 espécies. No segundo, os autores estudaram 31 espécies sul-americanas, sendo 13 brasileiras, pertencentes à subtribo Myrciinae, com o objetivo de verificar a possibilidade de separação dos gêneros através do uso da anatomia do lenho.

Em relação ao gênero Eugenia, Dadswell \& Ingle (1947), com base em estudos anatômicos do lenho e Chattaway (1959), em estudos da casca, confirmam a separação deste gênero em dois grupos: Syzigium, no Velho Mundo, e Eugenia, nas Américas. Van Wyk 
(1985) também realizou um extenso estudo da anatomia da casca de 12 espécies africanas de Eugenia, separando-as em dois grupos, através da morfologia externa e interna da casca.

O presente trabalho teve por objetivo estudar a anatomia de lenho e da casca de duas espécies de Myrtaceae, Eugenia cerasiflora e Eugenia uniflora, ocorrentes na Mata Atlântica, visando contribuir para a separação das mesmas, assim como para a taxonomia da família.

\section{Material e métodos}

A escolha do material foi feita com base no levantamento florístico realizado por Rossi (1994) na Mata da Cidade Universitária Armando de Salles Oliveira (CUASO), localizada na Cidade Universitária, São Paulo, Brasil. A área de estudo possui cerca de $102.100 \mathrm{~m}^{2}$, sendo parte da antiga cobertura florestal da cidade de São Paulo (Rossi 1994). Segundo Rizzini (1963) e Ab'Saber (1970), esta área pertence, respectivamente, à Província Atlântica e à Província Fitogeográfica das Matas Atlânticas. O clima, segundo Meguro et al. (1979), pode ser considerado temperado, quente e úmido, com estação menos chuvosa entre maio e setembro, apresentando umidade relativa de $80 \%$.

As espécies Eugenia cerasiflora Miq. e E. uniflora L. pertencem à subfamília Myrtoideae, tribo Myrteae, seguindo a classificação proposta por Berg (1857) e Niedenzu (1893).

O material botânico e o lenhoso encontram-se depositados, respectivamente, no Herbário (SPF) e na Xiloteca (SPFw) do Departamento de Botânica do IBUSP, conforme indicado na tabela 1.

As amostras foram coletadas à altura do peito (AP), a cerca de $1,5 \mathrm{~m}$ do solo, com auxílio de serrote e formão, e posterior-

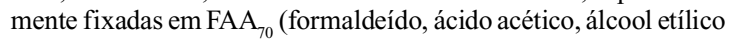
70 \%). Para a preparação dos corpos de prova, as amostras previamente fixadas, foram aparadas de modo que se obtivesse um cubo de aproximadamente $3 \mathrm{~cm}$ de aresta. As amostras passaram por um processo de fervura em água, por algumas horas, e posteriormente foram confeccionados cortes histológicos transversais, longitudinais tangenciais e radiais em microtómo de deslize Reichert. Os cortes sofreram desidratação em série etílica para posterior coloração em safranina $1 \%$ em etanol $50 \mathrm{GL}$, sendo montados em resina sintética.

Para o preparo das lâminas histológicas de casca as amostras foram incluídas em PEG (polietilenoglicol) 1500, segundo Gerlach (1984), seccionadas com o uso de fita adesiva (tesa film 106/ 4106), segundo Kruse (1977), em micrótomo de deslize Reichert.

Tabela 1: Espécimes analisados do gênero Eugenia.

\begin{tabular}{llccc}
\hline Espécie & $\mathrm{N}^{\circ}$ Coletor & $\begin{array}{c}\mathrm{N}^{\circ} \text { Herbário } \\
(\mathrm{SPF})\end{array}$ & $\begin{array}{c}\mathrm{N}^{\circ} \text { Xiloteca } \\
(\mathrm{SPW})\end{array}$ & $\begin{array}{c}\text { DAP } \\
(\mathrm{cm})\end{array}$ \\
\hline E. cerasiflora & P. Soffiatti 2 & 32165 & 806 & 18 \\
& P. Soffiatti 3 & 112563 & 807 & 21 \\
E. uniflora & P. Soffiatti 5 & 32158 & 808 & 16 \\
& P. Soffiatti 10 & 112580 & 809 & 20 \\
\hline DAP
\end{tabular}

$\mathrm{DAP}=$ diâmetro à altura do peito
Os cortes de casca foram corados com dupla e tripla coloração, utilizando-se os seguintes corantes: azul de astra $(1 \%)$, crisoidina $(0,5 \%)$, acroidina-crisoidina $(0,5 \%)$, verde iodo $(1 \%$ em etanol $95 \mathrm{GL})$ e hematoxilina (1\%), seguindo Angyalossy-Alfonso \& Richter (1991). O material dissociado seguiu a metodologia de Franklin (1945), sendo corado com safranina $1 \%$ em etanol 50 GL (lenho) e azul de astra 1\% (casca), e montado em lâminas semi-permanentes.

As características qualitativas obedeceram às recomendações do IAWA Committee (1989) para o lenho e Trockenbrodt (1990) e Richter et al. (1996) para a casca. As análises dos dados quantitativos foram realizadas segundo Eckblad (1991), sendo apresentados os resultados de seus valores mínimo - médio máximo.

\section{Resultados}

Descrição do lenho - Camadas de crescimento demarcadas por fibras de paredes espessadas em Eugenia cerasiflora (figura 1); em E. uniflora ocorre uma diminuição na freqüência dos vasos, juntamente com a presença de fibras com paredes espessadas (figura 2). Vasos com distribuição difusa (figuras 1 e 2); exclusivamente solitários (90\%) (figuras 1 e 2); diâmetro tangencial de (17-) 42 (-54) $\mu \mathrm{m}$; comprimento entre (286-) 528 (-812) $\mu \mathrm{m}$; com (38-) 69 (-177) vasos por $\mathrm{mm}^{2}$; placa de perfuração simples (figura 4); pontoações intervasculares alternas (figura 4), guarnecidas, com (4-) 5 (-5) $\mu \mathrm{m}$ de diâmetro; pontoações radio-vasculares similares às intervasculares. Traqueídes vasicêntricas presentes. Fibras com pontoações areoladas nas paredes tangencial e radial (figura 5), com paredes espessas a muito espessas (figura 3); (542-) 958 (-1247) $\mu \mathrm{m}$ de comprimento. Parênquima axial predominantemente apotraqueal, difuso a difuso em agregados em E. cerasiflora (figura 1); em E. uniflora, difuso em agregados e formando linhas com uma a três células de largura (figuras 2 e 3); série parenquimática constituída de oito a treze células por série (figura 6). Raios uni e multisseriados (uma a três células) (figuras 1-2,6), predominando aqueles com duas células de largura; heterogêneos, com corpo composto por células procumbentes e margens constituídas por uma a seis fileiras de células quadradas e eretas (figura 7). Inclusões orgânicas sob a forma de substância de coloração acastanhada nos vasos e em células do parênquima axial e radial em $E$. cerasiflora (figuras 4 e 7); em E. uniflora ocorrem em algumas células do parênquima radial (figura 6). Inclusões inorgânicas representadas por cristais prismáticos em células do parênquima axial; raros em $E$. cerasiflora; grandes e abundantes em E. uniflora, em 

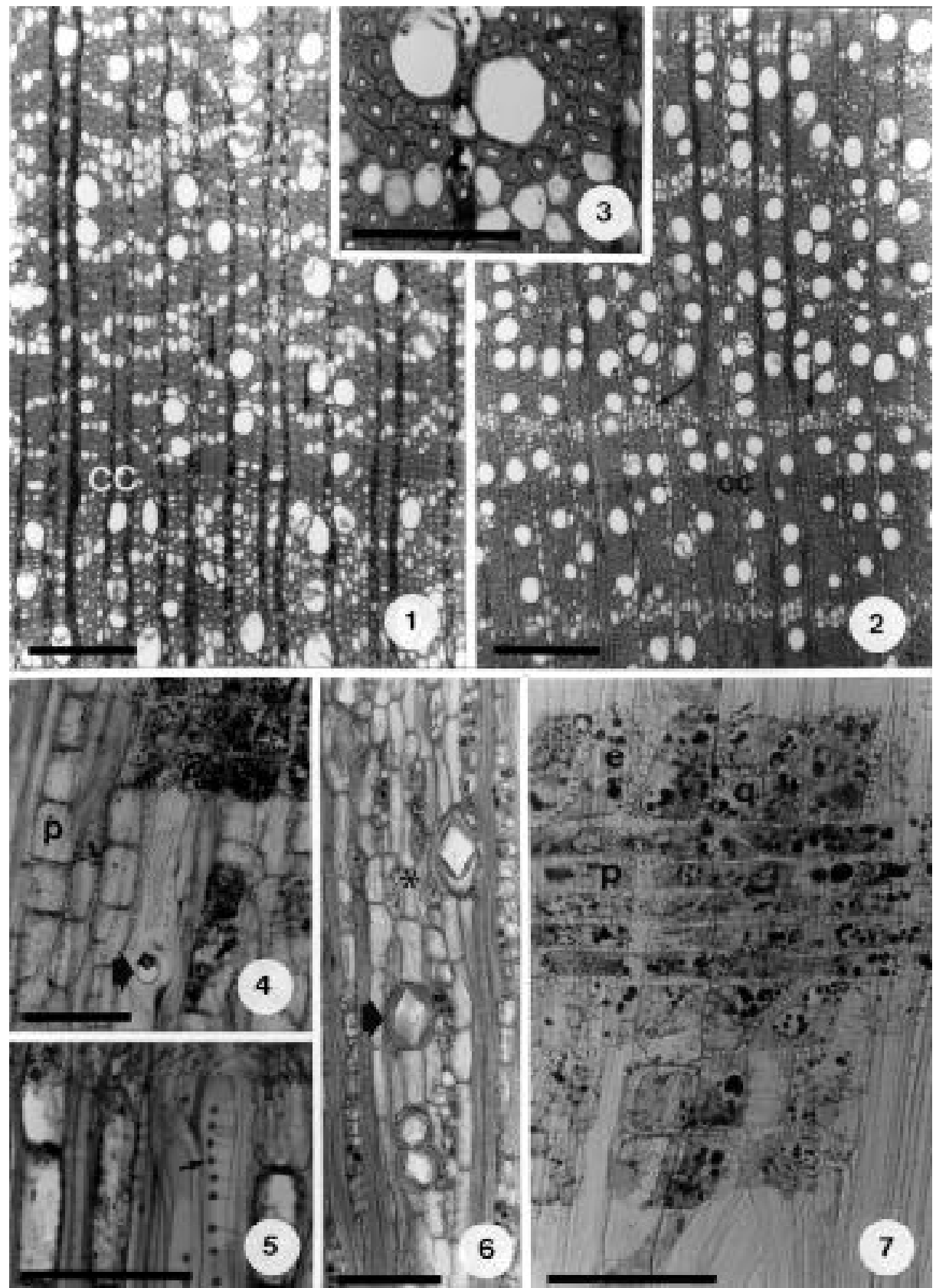

Figuras 1-7. Fotomicrografias de seções do lenho das espécies de Eugenia. 1: E. cerasiflora. Seção transversal. Vasos de porosidade difusa, solitários; parênquima axial difuso em agregados (seta); camada de crescimento delimitada por fibras de paredes espessadas (cc). Escala $=200 \mu \mathrm{m}$. 2-3: E. uniflora. Seção transversal. 2. Vasos de porosidade difusa, solitários; camada de crescimento demarcada por fibras de paredes espessadas (cc); parênquima axial formando linhas (setas). Escala $=200 \mu \mathrm{m}$. 3. Detalhe mostrando as fibras com paredes espessas; vasos solitários; parênquima axial; raios parenquimáticos com conteúdo escuro. Escala = $100 \mu$ m. 4-5. E. cerasiflora Seção longitudinal radial. Escala $=100 \mu \mathrm{m}$. 4. Placa de perfuração simples (seta); pontoações alternas; parênquima axial (p); células do parênquima radial com conteúdo. 5. Pontoações areoladas nas paredes das fibras, e sua comunicação com outro elemento traqueal (seta). 6: E. uniflora. Seção longitudinal tangencial. Cristais prismáticos grandes em células do parênquima axial (seta); série parenquimática (*). Escala $=50 \mu \mathrm{m}$. 7. E. cerasiflora. Seção longitudinal radial. Células procumbentes (p), eretas (e) e quadradas (q) do raio. Escala $=100 \mu \mathrm{m}$ 
células normais ou subdivididas do parênquima axial, maiores do que as adjacentes (figura 6).

Descrição da casca - Casca com 3 - 5 mm de espessura; semi-decídua. Organização geral (figuras 8 e 9): o floema caracteriza-se pela alternância de células vivas com células esclerificadas, as quais distribuem-se em grupos, como em E. cerasiflora (figuras 8 e 11) ou em faixas, em $E$. uniflora (figuras 9 e 14). Em $E$. uniflora, no floema externo, ocorre a dilatação dos raios (figura 9), que sofrem gradativamente, em direção à periferia, divisão e expansão das células; em $E$. cerasiflora, os raios dilatados confundem-se com as células parenquimáticas axiais, também dilatadas, formando um tecido de arranjo desordenado, denominado pseudocórtex (figuras 8 e 10). Em E. cerasiflora há apenas uma periderme (figura 10); o súber é compacto, formado por camadas de células de paredes delgadas alternadas com camadas de células lignificadas, com espessamento na parede tangencial interna ou uniformemente espessadas; células com diâmetro tangencial maior do que o radial (alongadas tangencialmente) e pontoações simples grandes; a feloderme é incipiente, formada por duas a quatro camadas de células parenquimáticas, de paredes delgadas, com conteúdo castanho; ocorrem cristais isolados no súber e na feloderme. Em E. uniflora há várias peridermes, formando ritidoma (figura 12); em cada periderme o súber é formado por uma, eventualmente duas camadas de células com diâmetro tangencial maior do que o radial (tangencialmente alongadas), com as paredes tangenciais internas espessadas (figura 13); a feloderme é formada por uma camada de células parenquimáticas, de paredes delgadas, com diâmetro radial maior do que o tangencial (alongadas radialmente); ocorrem eventualmente cristais no súber e na feloderme.

Elementos de tubo crivado predominantemente solitários em E. cerasifora e solitários ou formando grupos de dois a três em E. uniflora (figura 15); longos, com (177-) 416 (-754) $\mu \mathrm{m}$ de comprimento e placas crivadas compostas (figura 16), escalariformes, de orientação oblíqua (figuras 16 e 17), com (5-) 11 (17) áreas crivadas/placa; áreas crivadas laterais abundantes, células companheiras presentes (figura 15). Parênquima axial formado por dois tipos de células: as contendo substância de coloração acastanhada escura (figura 15) e as cristalíferas, formando séries contendo um cristal prismático por célula (figura 17). Fibras/fibroesclereídes em $E$. cerasiflora, representa-
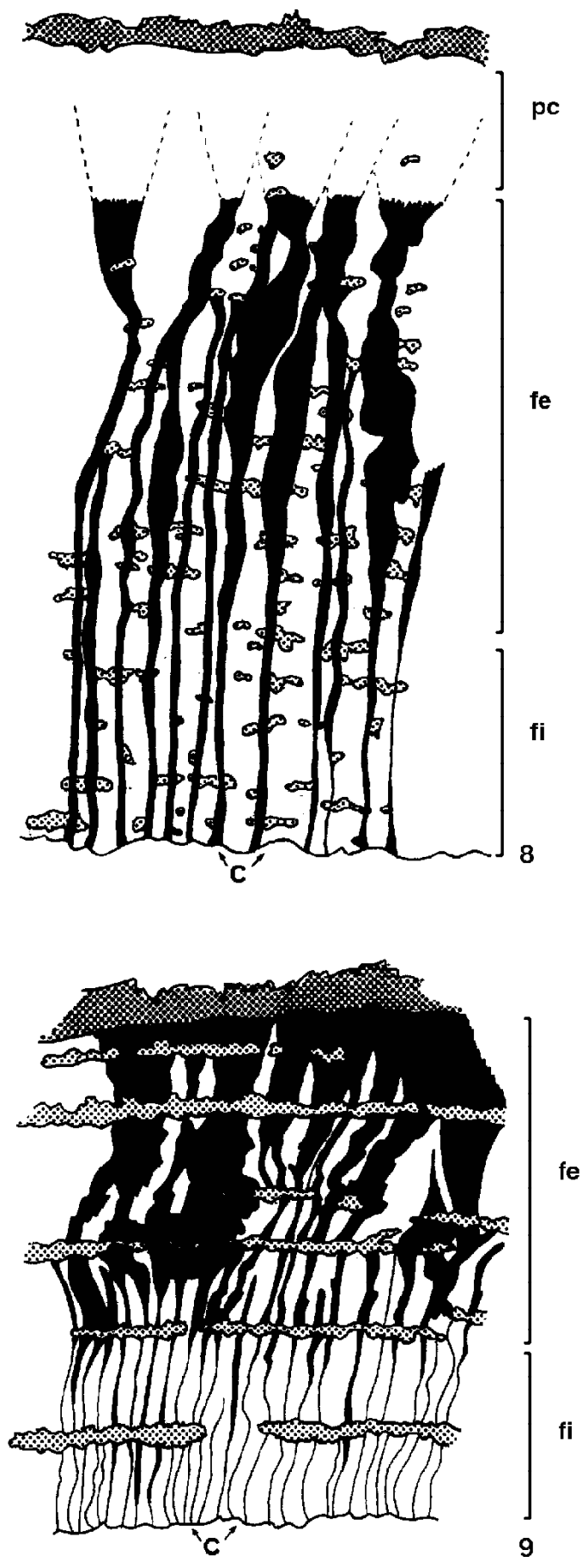

Figuras 8-9: Desenho esquemático da estrutura da casca em seç̧ão transversal. Escala $=50 \mu \mathrm{m}$. 8: E. cerasiflora. 9: E. uniflora. $\mathrm{pc}=$ pseudocórtex; fe = floema externo; fi = floema interno; c = câmbio; periderme/ritidoma; $\$$ tecido esclerificado; raios parenquimáticos. 
das por elementos esclerificados alongados (figura 19), semelhantes a fibras, dispostas em pequenos grupos (figuras 8 e 11). Esclereídes em E. uniflora, agregadas, formando faixas tangenciais (figuras 9 e 14); diferenciam-se próximo à região cambial (figura 14); retangulares a polimórficas (figura 20), com paredes polilameladas (figura 21), e projeções laterais na parede adjacente às séries cristalíferas, que suportam cada compartimento cristalífero (figura 22). Raios heterocelulares, com corpo formado por células procumbentes e as margens por duas a seis camadas de células quadradas e eretas; uni e multisseriados, com duas a três células de largura (figura 17); com (11-) 14 ( -17) raios $/ \mathrm{mm}$; altura de (126-) 289 (-591) $\mu \mathrm{m}$; no floema interno apresenta orientação retilínea a partir do câmbio (figuras 8 e 9); porções que atravessam ou são adjacentes às esclereídes lignificam-
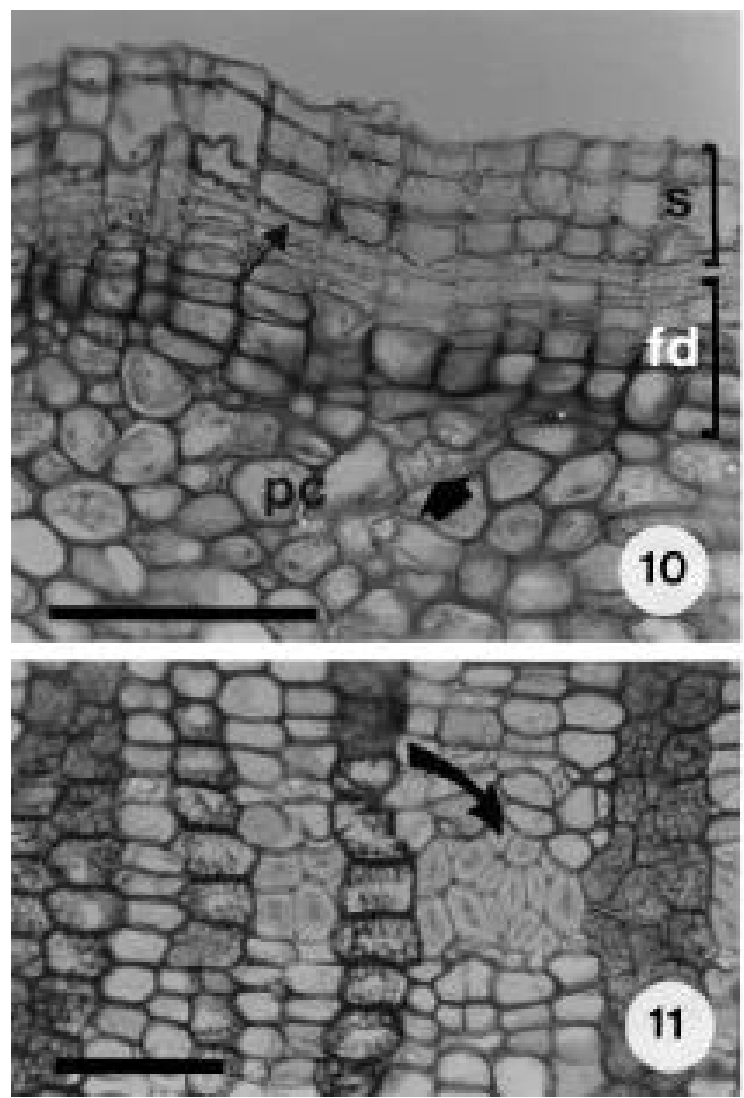

se em E. uniflora (figura 18), o que raramente é observado em E. cerasiflora; presença de substância de coloração acastanhada escura (figuras 15 e 18).

Tecido de dilatação derivado predominantemente do parênquima radial (figuras 8 e 9) e de células do parênquima axial. Em E. cerasiflora observa-se uma larga faixa de tecido parenquimático localizado entre a periderme e o tecido de dilatação (figuras 8 e 10), denominado pseudocórtex, aí podendo-se encontrar algumas células contendo cristais prismáticos (figura 10). Cristais prismáticos em séries cristalíferas do parênquima axial (figuras 16 e 17). Inclusões orgânicas sob a forma de substância de coloração acastanhada no parênquima axial e radial (figura 15).

A tabela 2 apresenta as características das duas espécies de Eugenia estudadas.

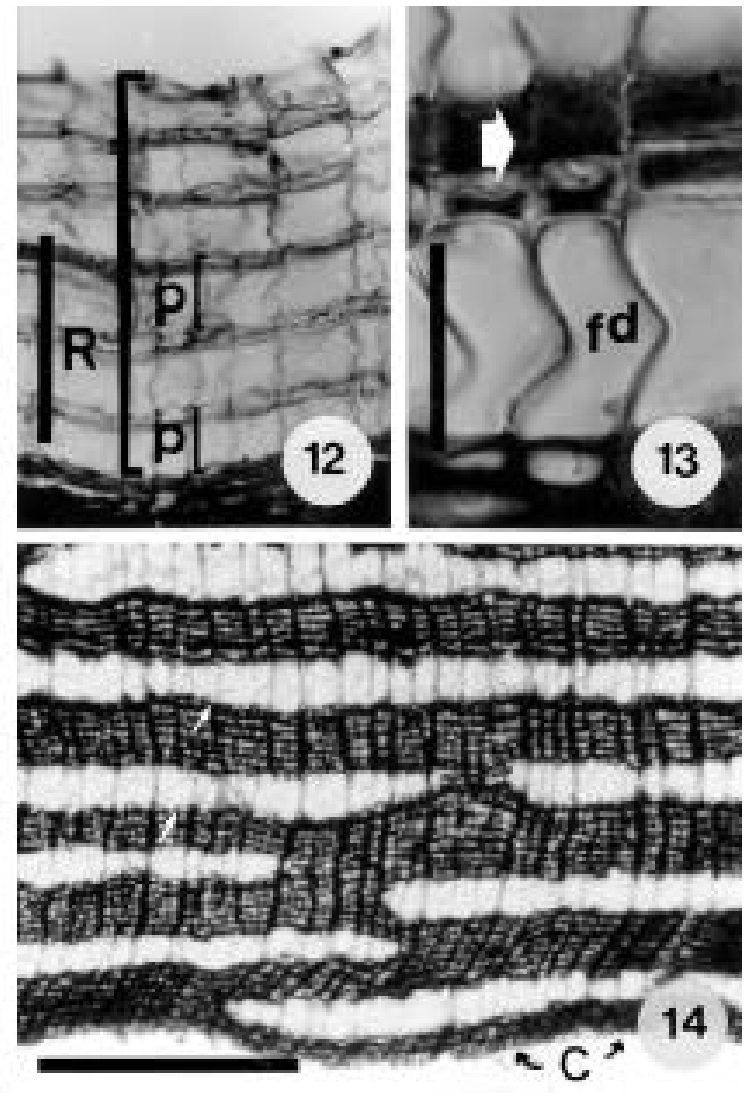

Figuras 10-14. Fotomicrografias de seções transversais da casca nas espécies de Eugenia. 10-11. E. cerasiflora. Escala $=100 \mu \mathrm{m} .10$. Periderme: súber (s), felogênio (seta menor), feloderme (fd) e idioblasto contendo cristal prismático (seta maior); pseudocórtex (pc). 11. Detalhe do arranjo das fibras (seta) no floema interno. 12-14. E. uniflora. 12. Ritidoma (R); peridermes (p). Escala = $100 \mu \mathrm{m} .13$. Detalhe periderme: feloderme (fd), súber (seta). Escala $=25 \mu \mathrm{m}$. 14. Arranjo em faixa das esclereídes (seta), que se alternam com as células vivas no floema interno, em luz polarizada. $\mathrm{c}=$ região cambial. Escala $=500 \mu \mathrm{m}$. 

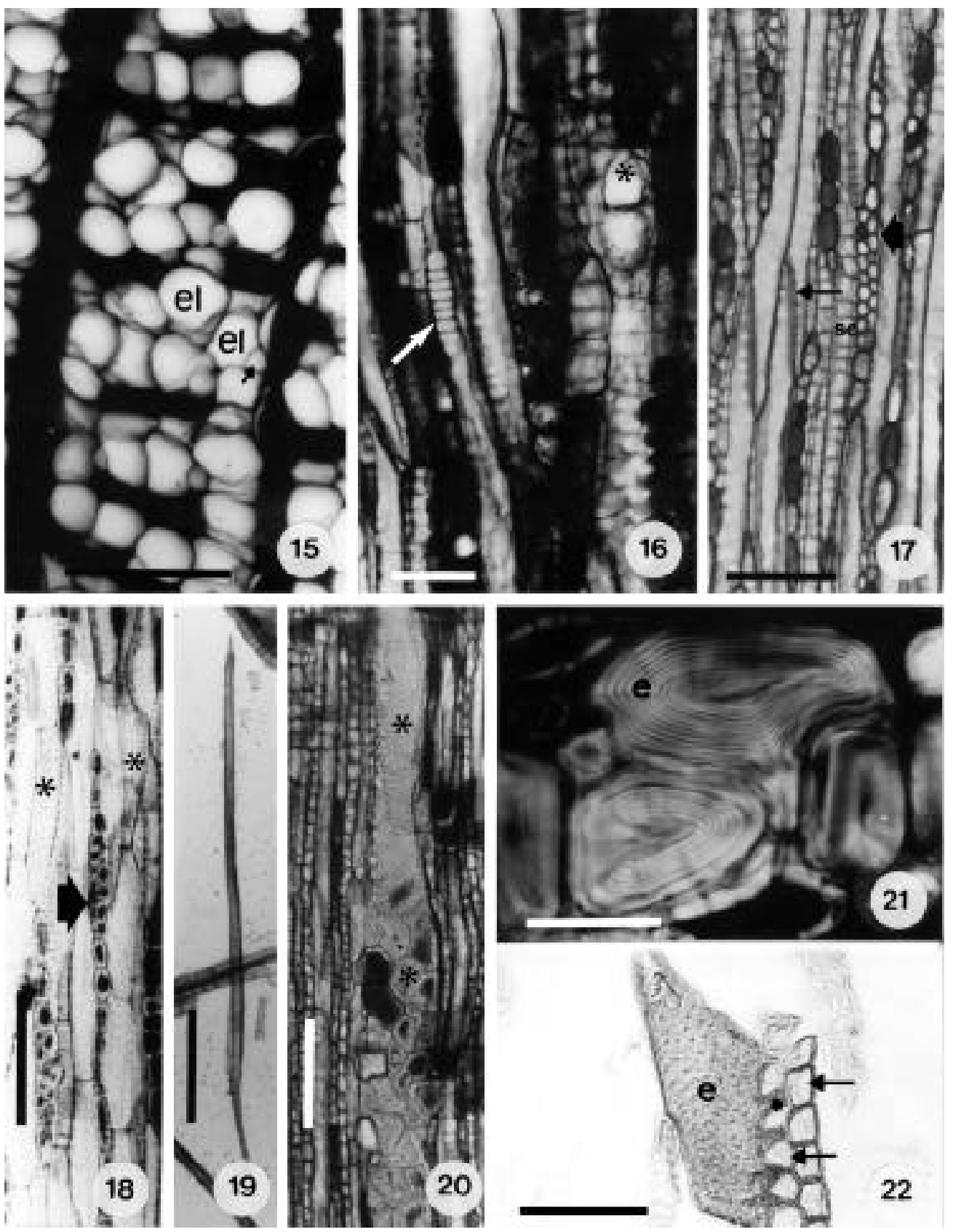

Figuras 15-22. Fotomicrografias de seções da casca das espécies de Eugenia. 15-18. E. uniflora. 15. Seção transversal. Elemento de tubo crivado (el) e células companheiras (seta). Escala $=50 \mu \mathrm{m}$. 16. Seção longitudinal tangencial. Placa crivada composta (seta) com nove áreas crivadas; observe os grandes cristais prismáticos $(*)$. Escala $=50 \mu \mathrm{m}$. 17. Seção longitudinal tangencial. Placas crivadas oblíquas (seta); observe séries cristalíferas (sc) e raios parenquimáticos com duas células de largura (seta maior). Escala $=100 \mu \mathrm{m} .18$. Seção longitudinal tangencial. Raios com células de paredes lignificadas (seta), com conteúdo castanho; note as séries de esclereídes ${ }^{*}$ ). Escala $=100 \mu \mathrm{m}$. 19. E. cerasiflora. Fibra/fibroesclereíde dissociada. Escala $=250 \mu \mathrm{m} .20-22$. E. uniflora. 20 . Seção longitudinal radial. Esclereídes $(*)$, algumas com conteúdo. Escala $=100 \mu \mathrm{m}$. 21. Seção transversal. Detalhe das esclereídes (e) com paredes polilameladas. Escala $=100 \mu \mathrm{m}$. 22. Esclereíde (e) unida à série cristalífera sem cristais (setas) devido ao método utilizado para dissociar o material (Jeffrey). Note a projeção da parede da esclereíde (*). Escala $=50 \mu \mathrm{m}$. 
Tabela 2: Caracteres anatômicos do lenho e da casca para as espécies de Eugenia estudadas.

\begin{tabular}{|c|c|c|c|}
\hline Caracteres & & Eugenia cerasiflora & Eugenia uniflora \\
\hline \multirow[t]{2}{*}{ Lenho } & Parênquima axial & difuso & difuso; linha \\
\hline & Cristais & raros & abundantes \\
\hline \multirow[t]{7}{*}{ Casca } & Esclerênquima: & & \\
\hline & Esclereídes & - & + \\
\hline & Fibras / fibroesclereídes & + & - \\
\hline & Arranjo & $\begin{array}{l}\text { em grupos ou arranjos } \\
\text { tangexiais descontínuos }\end{array}$ & faixas tangenciais \\
\hline & Ritidoma & - & + \\
\hline & Periderme & $\begin{array}{l}\text { células vivas alternadas com } \\
\text { células esclerificadas }\end{array}$ & $\begin{array}{l}\text { células com espessamento na parede } \\
\text { tangencial interna }\end{array}$ \\
\hline & feloderme & 2-3 camadas de células & 2-3 camadas de células \\
\hline
\end{tabular}

$+=$ presença; $-=$ ausência

\section{Discussão}

As espécies estudadas Eugenia cerasiflora e E. uniflora apresentam estrutura do lenho semelhante, do ponto de vista qualitativo, com a presença de vasos com distribuição difusa, predominantemente solitários, placa de perfuração simples, pontoações intervasculares alternas e guarnecidas, e traqueídes associadas aos vasos. Estas características corroboram informações prévias descritas para a família Myrtaceae por outros autores, tais como: Dadswell \& Ingle (1947), Metcalfe \& Chalk (1950), Détienne \& Jacquet (1983).

Com relação ao lenho, as espécies podem ser diferenciadas quanto ao tipo de parênquima axial e a presença de cristais (tabela 2). Dias-Leme et al. (1995), verificaram que é muito difícil a separação de espécies do gênero Myrcia, com base apenas na anatomia do lenho, pois esta é muito similar. Quanto ao parênquima axial, por exemplo, há toda uma gradação desde parênquima difuso até difuso em agregados e em linhas, não sendo, portanto, um bom caráter para a separação das espécies.

Détienne \& Jacquet (1983), estudando várias espécies de Eugenia da Amazônia, observaram também uma variação interespecífica quanto ao tipo de parênquima axial, destacando o predomínio do tipo difuso a difuso em agregados em E. cerasiflora e em linhas em E. uniflora, sendo uma característica que, neste caso, pode ser utilizada como critério para separação destas espécies.
De acordo com Van Vliet \& Baas (1984) cristais prismáticos, muitas vezes grandes, inclusos em idioblastos, são de ocorrência comum em algumas espécies de Myrtaceae. Nas espécies de Myrcia estudadas por Dias-Leme et al. (1995) ocorrem cristais prismáticos em séries parenquimáticas e os autores comentam que a presença e distribuição destes pode ter valor diagnóstico. Esse fato pôde ser constatado quanto às duas espécies de Eugenia estudadas no presente trabalho, sendo que a presença de cristais romboidais grandes em $E$. uniflora pode ser assumida como um carater diagnóstico para a espécie.

A composição celular dos raios de E. cerasiflora e E. uniflora e a predominância de raios bisseriados é semelhante ao observado por Détienne \& Jacquet (1983), para as espécies amazônicas e por Mainieri \& Chimelo (1989), para uma espécie de Eugenia não identificada. Entretanto, quanto ao diâmetro tangencial dos elementos de vaso, o valor encontrado foi menor do que o observado pelos mesmos autores.

Quanto à anatomia da casca, observam-se diferenças muito mais evidentes do que as encontradas no lenho, conforme mencionado na tabela 2 . As duas espécies estudadas apresentam tipos de periderme $\mathrm{e}$ células esclerificadas bastante distintos.

O esclerênquima é um dos caracteres mais marcantes na distinção das espécies estudadas sendo que, segundo Esau (1964), o mesmo está dentre os tipos celulares mais comumente encontrados no floema secundário. 
As células esclerificadas observadas correspondem a esclereídes e a fibras/fibroesclereídes. As esclereídes diferenciam-se a partir de células parenquimáticas e são de fácil reconhecimento, podendo se apresentar de várias formas: geralmente são células curtas, com paredes muito espessadas e polilameladas (Esau 1964, Parameswaran 1980, Trockenbrodt 1990). Em E. uniflora ocorrem esclereídes curtas com paredes polilameladas, como relatado por Chattaway (1959) no estudo da mesma espécie, onde a autora denomina esclereídes colunares. Em E. cerasiflora verifica-se a ocorrência de células esclerificadas alongadas, semelhantes às fibras. Entretanto, em algumas observam-se paredes polilameladas o que, segundo Parameswaran (1980), é um caráter para distinção entre fibras verdadeiras e fibroesclereídes. Vários autores (Zahur 1959, Esau 1964, Parameswaran 1980, Trockenbrodt 1990) definem fibras floemáticas verdadeiras como aquelas produzidas diretamente pelas iniciais fusiformes, e fibroesclereídes como fibras que se desenvolvem a partir de células parenquimáticas, apresentando ambas a mesma morfologia. Somente um estudo de desenvolvimento permitiria inferências concretas sobre a real natureza dessas células nas espécies estudadas.

Chattaway (1953) e Bamber (1962) mencionam que a ocorrência de fibroesclereídes em algumas espécies de Leptospermoideae (Myrtaceae) é de importância taxonômica. Roth (1981), no estudo de cinco espécies de Eugenia, também considera o arranjo do tecido esclerificado como uma caráter importante para fins diagnósticos, embora a autora somente tenha observado o que denominou de fibras floemáticas. Não se observou em E. cerasiflora e E. uniflora variação intraespecífica no arranjo e na distribuição das células esclerificadas, como constatado por Van Wyk (1985) no estudo de espécies africanas de Eugenia.

Em E. uniflora observou-se uma esclerificação dos raios parenquimáticos que atravessam ou são adjacentes às esclereídes, como observado por Van Wyk (1985), além de vários outros autores, em estudos com espécies de outras famílias (Parameswaran \& Liese 1972, Richter 1981, Angyalossy-Alfonso \& Richter 1991). Já em E. cerasiflora esse fenômeno não foi observado, provavelmente porque a quantidade de esclerênquima é muito menor do que em $E$. uniflora.
O tecido de dilatação nas espécies estudadas é composto principalmente pelos raios. Essa característica foi observada somente em duas espécies sulamericanas de Eugenia (Roth 1981). Chattaway (1953) menciona que em Myrtaceae, geralmente, o tecido de dilatação é formado pelo parênquima axial, como em Eucalyptus, como também observado por Angyalossy-Alfonso (1987).

Seguindo a definição de Van Wyk (1985), a extensa região parenquimática observada abaixo da periderme em E. cerasiflora pode ser considerada um pseudocórtex, compreendendo as células do córtex propriamente dito, misturadas às células parenquimáticas originadas do floema secundário, com alguns idioblastos contendo drusas.

Cristais, geralmente de carbonato de cálcio, são muito comuns no floema secundário de angiospermas (Parameswaran \& Liese 1972, Roth 1981). Segundo Metcalfe \& Chalk (1983), a sua forma e distribuição pode ter valor taxonômico. Roth (1981) afirma que a presença de séries cristalíferas é diagnóstico na distinção de espécies, gêneros e famílias, incluindo as Myrtaceae. Nas duas espécies analisadas observa-se abundância de cristais, tanto no floema interno (funcional) quanto no externo (não-funcional), em séries cristalíferas do parênquima axial, discordando de Roth (1981) que menciona sua presença em maior quantidade no floema não-funcional, relacionando sua formação à esclerificação das células. Observou-se que as fibras/fibroesclereídes ou esclereídes adjacentes às séries cristalíferas apresentam projeções na sua parede, como também observado por Van Wyk (1985).

As espécies estudadas apresentam elementos de tubo crivados longos, com placas crivadas oblíquas, compostas. Seguindo os padrões estabelecidos por Zahur (1959), tais células seriam do tipo intermediário entre o tipo mais primitivo-longo e o mais derivado-curto, com placas crivadas do tipo I (mais primitiva): inclinadas, compostas, com muitas áreas crivadas. Carlquist (1975) menciona que a evolução dos elementos de tubo crivados longos, com placas crivadas oblíquas para o tipo curto, com placas transversais, seguiu a mesma linha de evolução dos elementos de vaso, não obrigatoriamente ao mesmo tempo. Ainda segundo o autor, numa mesma espécie e/ou órgão, o elemento de vaso pode apresentar-se com características mais derivadas do que o elemento de tubo crivado. No presente traba- 
lho, observa-se que as espécies apresentam os elementos de vaso com placa de perfuração simples, transversal, enquanto que as placas crivadas são compostas e oblíquas nos elementos de tubo crivado. As células companheiras são de difícil observação em seção longitudinal, como também verificado por Van Wyk (1985), geralmente apresentandose uma por elemento.

As peridermes das espécies estudadas são distintas. E. uniflora apresenta ritidoma, onde cada periderme possui um súber composto por uma ou duas camadas de células tangencialmente alongadas, e a feloderme composta por uma camada de células com paredes delgadas, semelhante a Eucalyptus cloeziana (Angyalossy-Alfonso 1987). E. cerasiflora não forma ritidoma; a periderme constitui-se de um súber composto por várias camadas de células de paredes delgadas alternadas com células de paredes lignificadas e a feloderme incipiente, com duas ou três camadas de células parenquimáticas de paredes delgadas e conteúdo de coloração castanha. Este padrão é similar à periderme de E. patriisi, descrita por Roth (1981).

Pode-se concluir, através do presente trabalho, que o estudo da anatomia da casca complementa e supera o da anatomia do lenho na caracterização e distinção das duas espécies de Eugenia. As características da periderme, a presença de fibras/fibroesclereídes e esclereídes e a disposição destas no tecido floemático, mostraram-se muito distintas, distanciando as espécies. Os resultados deste trabalho sugerem que a casca seja levada em consideração em estudos de identificação de espécies, sempre em associação ao lenho.

\section{Referências bibliográficas}

AB'SABER, A.N. 1970. O mosaico primário de matas e cerrados do Planalto Paulista. In I Simpósio de Ecologia Intertropical, Salvador. Publ. Inst. de Geograf. da Univ. S. Paulo, série Cadernos de Ciências da Terra 6:24-26.

ANGYALOSSY-ALFONSO, V. 1983. Caracterização anatômica da madeira e casca das principais espécies de Eucalyptus do estado de São Paulo. Silvicultura: 28:720-725.

ANGYALOSSY-ALFONSO, V. 1987. Caracterização anatômica da casca das principais espécies de Eucalyptus L'Hérit cultivadas no Brasil. Tese de doutorado, Universidade de São Paulo, São Paulo.

ANGYALOSSY-ALFONSO, V. \& RICHTER, H.G. 1991. Wood and bark anatomy of Buchenavia Eichl. (Combretaceae). IAWA Bull. 12:123-141.

BAMBER, R.K. 1962. The anatomy of the barks of Leptospermoideae. Aust. J. Bot. 10:25-54
BERG, O.K. 1857. Myrtaceae. In Flora Brasiliensis. (K.P. von Martius, A. G. Eichler \& I. Urban, eds.) v.14, p.1-655.

CARLQUIST, S. 1975. Ecological strategies of xylem evolution. Univ. of California Press, Berkeley.

CHATTAWAY, M.M. 1953. The anatomy of bark. I. The genus Eucalyptus. Aust. J. Bot. 1:402-433.

CHATTAWAY, M.M. 1959. The anatomy of bark. VII. Species of Eugenia (sens. lat.). Trop. Woods 111:1-14.

DADSWELL, H.E. 1972. The anatomy of the Eucalyptus woods. Commonwealth Scientific and Industrial Research Organization. Melbourne. Division of Applied Chemistry Technological Paper 66.

DADSWELL, H.E. \& BURNELL, M. 1932. Methods for the identification of the coloured woods of the genus Eucalyptus. Council for Scientific and Industrial Research, Melbourne. Division of Forest Products Technical Paper 5.

DADSWELL, H. E. \& INGLE, H. D. 1947. The wood anatomy of the Myrtaceae I. Trop. Woods 90:1-7.

DÉTIENNE, P. \& JACQUET, P. 1983. Atlas d'identification des bois de l'amazonie et des régions voisines. Centre Technique Forestier Tropical, Nogent-sur-Marne.

DIAS-LEME, C.L., GASSON, P. \& LUGHADA, E.N. 1995. Wood anatomy of four Myrtaceae genera in the subtribe Myrciinae from South America. IAWA J. 16:87-95.

ECKBLAD, J.W. 1991. How many samples should be taken? BioScience 41:346-348.

ESAU, K. 1964. Structure and development of the bark in dicotyledons. In The formation of wood in forest trees (M. H. Zimmerman, ed.) Academic Press, New York.

FRANKLIN, L. 1945. Preparation of thin sections os synthetic resins and wood. Resin composites, and a new macerating method for wood. Nature 155:51.

GERLACH, D. 1984. Botanische Mikrotechnik. Georg Thieme Verlag, Stuttgart.

IAWA COMMITTEE. Committee of the International Association of Wood Anatomists. 1989. IAWA List of microscopic features for hardwood identification. IAWA Bull. 10:219-332.

KRUSE, J. 1977. Mikrotechnologische und biologische Untersuchungen an Rindenplatten. Dissertation, Fachbereich Biologie, Universität Hamburg.

MAINIERI, C. \& CHIMELO, J.P. 1989. Fichas de características das madeiras brasileiras. IPT, Instituto de Pesquisas Tecnológicas - Divisão de Madeiras, São Paulo.

MEGURO, M., VINUEZA, G.N. \& DELITTI, W.B. C. 1979. Ciclagem de nutrientes minerais na mata mesófila secundária. I. Produção e decomposição de folhas. Bol. Bot. Univ. S. Paulo 7:11-31.

METCALFE, C.R. \& CHALK, L. 1950. Anatomy of the dicotyledons. 2 vols. Clarendon Press, Oxford.

METCALFE, C.R. \& CHALK, L. 1983. Anatomy of the dicotyledons. Vol. II. Wood structure and conclusion of the general introduction. $2^{\mathrm{a}}$ ed. Clarendon Press, Oxford.

NIEDENZU, F. 1893. Myrtaceae. In Die natürlichen Pflanzenfamilien. (A. Engler, \& K. Prantl, ed.) 3:57-105.

PARAMESWARAN, N. 1980. Some remarks on the nomenclature of fibres, sclereids and fibre-sclereids in the secondary phloem of trees. IAWA Bull. 1:130-132.

PARAMESWARAN, N. \& LIESE, M. 1972. Studies in bark anatomy. IAWA Bull. 3:12-16.

RICHTER, H. G. 1981. Wood and bark anatomy of Lauraceae I. Aniba Aublet. IAWA Bull. 2:79 - 87.

RICHTER, H.G., MAZZONI-VIVEIROS, S.C., ALVES, E.S., LUCHI, A.E. \& COSTA, C.G. 1996. Padronização de critérios para a descrição anatômica da casca: lista de características e glossário de termos. IF-Sér. Reg. S. Paulo 16:1-25. 
RIZZINI, C. T. 1963. Nota prévia sobre a divisão fitogeográfica (florístico sociológica) do Brasil. Revta. bras. Geogr. 25:3-64.

ROSSI, L. 1994. A flora arbóreo-arbustiva da mata da reserva da cidade universitária "Armando de Salles Oliveira" (São Pau1o, Brasil). Bol.Bot.Univ.S.Paulo 9:1-105.

ROTH, I. 1981. Structural patterns of tropical barks. Gebrüder Borntraeger, Berlin.

TOMAZZELO FILHO, M. 1985. Estrutura anatômica da madeira de oito espécies de Eucalyptus cultivadas no Brasil. IPEF 29:25-36.

TROCKENBRODT, M. 1990. Survey and discussion of the terminology used in bark anatomy. IAWA Bull. 11:141-166.
TROCKENBRODT, M. \& PARAMESWARAN, N. 1986. A contribution to the taxonomy of the genus Inga Scop. (Mimosaceae) based on the anatomy of the secondary phloem. IAWA Bull. 7:62-71.

VAN VLIET, G.J.C.M. \& BAAS, P. 1984. Wood anatomy and classification of Myrtales. Ann. Missouri Bot. Gard. 71:783-800.

VAN WYK, A.E. 1985. The genus Eugenia (Myrtaceae) in Southern Africa: Structure and taxonomic value of bark. S. Afr. J. Bot. 51:157-180.

ZAHUR, M.S. 1959. Comparative study of secondary phloem of 423 species of woody dicotyledons belonging to 85 families. Cornell Univ. Agric. Exp. Station Mem. 35:1-160. 